\title{
Men's Conformity to Traditional Masculinity and Relationship Satisfaction
}

\author{
Shawn Meghan Burn and A. Zachary Ward \\ California Polytechnic State University, San Luis Obispo
}

\begin{abstract}
The Conformity to Masculine Norms Inventory (CMNI), intended as a counseling tool to examine masculinity issues with male clients, assesses conformity to 12 components of the masculine role. In this study, participants $(N=307)$ completed the CMNI and the Relationship Assessment Scale (RAS). Men's conformity to traditional masculine norms was negatively associated with RAS scores for both men rating themselves and women rating their male partners on the CMNI. Men's conformity to masculine norms was more strongly associated with women's relationship satisfaction than with men's relationship satisfaction. Findings suggest the usefulness of the CMNI for helping counseling clients explore how men's conformity to specific masculine norms is connected to the quality of their romantic relationships.
\end{abstract}

Past research supports the common stereotype that in comparison with women, men may be deficient in relationship skills. For instance, willingness to self-disclose personal information, thoughts, and feelings increases relationship satisfaction for both men and women (Boyd, 1995; D. C. Jones, 1991; Siavelis \& Lamke, 1992), but men are less emotionally expressive and self-disclose significantly less than their female counterparts (Dindia \& Allen, 1992; Foubert \& Sholley, 1996; Stapley \& Haviland, 1989). Both men and women report that their relationships with women are higher in intimacy, enjoyment, and nurturance (Sapadin, 1988). Women are better listeners than men (Miller, Berg, \& Archer, 1983), and they serve as greater sources of social support (Cutrona, 1996). In marital relationships, women are more likely to confront marital problems and men are more likely to stonewall and become defensive (Gottman, 1994).

Although some lay the cause of such gender differences at the doorstep of biological gender differences, many believe that the primary culprit is the traditional masculine role. According to Levant (1996), there is a "crisis of connection" between heterosexual men and women, and a new psychology of men is essential for the enhancement of gender relations. This new psychology of men suggests that the relationship difficulties experienced by some men stem from the norms of the traditional masculine role. In addition, the presumption is that an increased understanding of the dysfunctional aspects of traditional masculinity can lead to improved psychological services for men and can reduce relationship distress.

The gender role strain paradigm (Pleck, 1981, 1995) provides a framework in which the relationship between traditional masculinity and relationship dysfunction may be understood. It proposes that the male gender role stems from masculinity ideologies (male gender role stereotypes and norms) that are learned via socialization. Thompson and Pleck (1986) suggested that the structure of traditional masculinity ideology consists of three sets of norms: toughness, success-status, and antifemininity. The Masculine Role Norms Scale (Thompson \& Pleck, 1986) measures endorsement of these norms using a 
set of 26 Likert-scaled statements. Toughness includes physical, mental, and emotional toughness (e.g., "A man must stand on his own two feet and never depend on other people to help him do things"). Men are expected to be physically strong and masculine, highly competent and knowledgeable, and able to solve their own emotional difficulties and avoid showing vulnerability. The success-status norm is described as the expectation that men succeed in their professional careers, which is often measured by income (e.g., "Success in his work has to be a man's central goal in this life"). Finally, the antifemininity norm is the belief that men should avoid stereotypically female activities, behaviors, or occupations (e.g., "It bothers me when a man does something I consider 'feminine"'). A later measure, the 56-item Male Role Norms Inventory (Levant et al., 1992) also assesses endorsement of the norms that make up the male role but adds the dimensions of selfreliance (e.g., "A man should never count on someone else to get the job done"), homophobia (e.g., "A man should be able to openly show affection to another man"), aggression (e.g., "When the going gets tough, men should get tough"), and sexual attitudes (e.g., "A man should always be ready for sex").

According to the gender role strain paradigm, these socially constructed masculinity ideologies give rise to male gender role strain (Pleck, 1995). Discrepancy strain occurs when men have difficulty living up to the masculine standards they have internalized. This discrepancy produces what is sometimes called gender role conflict, a psychological state in which socialized gender roles have negative consequences on the person or others (O'Neil, Good, \& Holmes, 1995; O'Neil, Helms, Gable, David, \& Wrightsman, 1986). The Gender Role Conflict Scale (O'Neil et al., 1986) measures the anxiety and distress men may experience because of traditional gender role expectations. It is a 37item scale that assesses four areas of gender role conflict in men: success, power, and competition (e.g., "I worry about failing and how it affects my doing well as a man"); restrictive emotionality (e.g., "I have difficulty expressing my emotional needs to my partner"); restrictive affectionate behavior between men (e.g., "Affection with other men makes me tense"); and conflict between work and family relations (e.g., "My needs to work or study keep me from my family or leisure more than I would like"). Gender role conflict is expected to have negative effects on relationship intimacy and satisfaction because of its relationship to attitudes and behaviors that are harmful to interpersonal relationships (Rochlen \& Mahalik, 2004). For example, men who experience gender role conflict when expressing feelings may be less emotionally expressive, thus reducing relationship intimacy. Indeed, a number of studies have found that gender role conflict is associated with reduced relationship intimacy and reduced relationship satisfaction (Campbell \& Snow, 1992; Cournoyer \& Mahalik, 1995; Rochlen \& Mahalik, 2004; Sharpe \& Heppner, 1991; Sharpe, Heppner, \& Dixon, 1995).

Dysfunction strain describes the idea that fulfilling the requirements of the traditional male role may lead to negative outcomes for men and for their relationships with others. For example, men are socialized to compete and to value winning at the expense of intimacy, whereas women are socialized to value the romantic relationship and seek harmony and intimacy within it (G. P. Jones \& Dembo, 1989; Ruble \& Scheer, 1994). Men are also expected to be "tough" and are socialized to withhold their emotional feelings. Emotional expressiveness and self-disclosure are also identified as feminine qualities and, consequently, are to be avoided (Burn, 1996; O’Neil, 1981). Pleck (1995) cited research finding that traditional male role expectations foster commitment to work at the expense of marriage and family. Indeed, conformity to masculine norms is associated with a lower capacity for intimacy (Ludlow \& Mahalik, 2001), and marital satisfaction is linked to the degree to which one's partner has traditionally feminine traits, such as nurturance and being kind, gentle, affectionate, and other centered (Antill, 1983; Ickes, 1985; Kurdek \& Schmitt, 1986; Lamke, 1989; McGraw, 2001). Similar findings are found with dating couples (Lamke, Sollie, Durbin, \& Fitzpatrick, 1994; Siavelis \& Lamke, 1992). Pleck, Sonenstein, and Ku (1993) found that men with traditional masculine attitudes had more sexual partners, had less intimate relationships with women, and were more likely to view relationships between men and women as adversarial. After reviewing research from 1970 to 1990 , Ickes (1993) concluded that traditional 
masculinity is associated with reduced romantic relationship satisfaction.

\section{The Current Study}

The Conformity to Masculine Norms Inventory (CMNI; Mahalik et al., 2003) is one of the newest measures of traditional masculinity. Unlike past instruments that measure endorsement of the male role or the stress and conflict created by the male role, the CMNI focuses on conformity or nonconformity to masculine gender norms. The CMNI also assesses 11 different masculine norms "to be able to examine the great variability in how men enact masculinity" (Mahalik et al., 2003, pp. 5-6). The 11 norms are winning, emotional control, risk-taking, violence, dominance, playboy, self-reliance, primacy of work, power over women, disdain for homosexuals, and pursuit of status. The CMNI underwent extensive psychometric testing and has strong internal consistency, high construct validity, and high test-retest reliability (Ludlow \& Mahalik, 2001).

According to Ludlow and Mahalik (2001), the CMNI is intended as a tool for psychologists and counselors to examine masculinity issues with individual men, including how conformity to masculinity norms contributes to relationship stress. The instrument is new, however, and this assertion has not yet been empirically supported. This study uses the CMNI to test the hypothesis that conformity to the norms of traditional masculinity creates dysfunction strain because fulfilling the requirements of the traditional male role may lead to decreased relationship satisfaction. More specifically, the study hypotheses were as follows.

\section{Hypothesis 1}

Consistent with past research finding that masculinity is associated with reduced relationship intimacy, total CMNI scores were expected to be associated with reduced relationship satisfaction for both men and women.

\section{Hypothesis 2}

The Emotional Control, Self-Reliance, RiskTaking, Playboy, Power Over Women, Dominance, Violence, Winning, Pursuit of Status, and Primacy of Work subscales were all ex- pected to be negatively correlated with relationship satisfaction for both women and men. It was expected that the Emotional Control, SelfReliance, Risk-Taking, Primacy of Work, and Pursuit of Status subscales will be negatively correlated with relationship satisfaction because conformity to these norms may contraindicate physical and emotional availability and the interdependence necessary for relationship intimacy. Conformity to the Playboy, Dominance, Winning, and Power Over Women subscales was expected to be negatively related to relationship satisfaction because conformity to these norms may be experienced as disrespectful by women and may produce relational conflict. The Power Over Women, Dominance, and Violence subscales were also expected to be negatively associated with relationship satisfaction because they may lead to controlling behaviors and physical abuse and may be associated with men's negative attitudes toward women. The Winning subscale was also expected to be negatively associated with relationship satisfaction because it may translate into a competitive orientation that interferes with cooperative conflict resolution. No prediction was made regarding the Disdain for Homosexuals subscale.

\section{Hypothesis 3}

The relationship between CMNI scores and relationship satisfaction was expected to be stronger for women rating their male partners than for men rating themselves. The CMNI and the CMNI subscales were expected to account for a greater portion of the variance in relationship satisfaction for women in comparison with men. This was expected because some research suggests that men's satisfaction is based more on instrumental concerns (such as regular sexual relations or the division of household labor), whereas women's satisfaction is based on interdependence and communication (Burleson, Kunkel, Samter, \& Werking, 1996). Under this scenario, conformity to the masculine role would affect the sources of women's relationship satisfaction more than men's. Alternatively, other research finds that both men's and women's relational standards are similar and determined by whether emotional needs are met (Vangelisti \& Daly, 1997). If this is the case, then male partners' conformity to masculine 
norms may influence women's satisfaction more than men's satisfaction because it may greatly reduce the emotional support women receive from male partners versus the emotional support men receive from female partners.

\section{Method}

\section{Research Participants}

Participants were 137 female and 170 male introductory psychology students (mean age 20.2 years, $S D=1.15$ ) at a central California university from 44 different majors. The majority $(61.2 \%)$ were 1 st-year students. Ethnicity was primarily Euro American (79.3\%), followed respectively by Asian Americans (9.5\%), Latin Americans-Hispanics (5.9\%), African Americans (1.6\%) and Pacific Islanders (1.6\%), those who described themselves as other $(1.3 \%)$, and Middle Easterners $(0.7 \%)$. Some $(0.7 \%)$ declined to specify their ethnicity.

\section{Materials}

CMNI. The CMNI was developed by Mahalik et al. (2003) and consists of 11 subscales (94 items) measuring conformity to traditional masculine norms. Respondents indicate the extent of agreement using a 4-point Likert scale $(1=$ strongly disagree, $2=$ disagree, $3=$ agree, and $4=$ strongly agree). Subscale items are averaged (subscales have different numbers of items), and then subscale means are summed for a total CMNI score. Examples of items from each subscale are as follows: Winning (10 items), "In general, I will do anything to win;" Emotional Control (11 items), "I tend to keep my feelings to myself;" Risk-Taking (10 items), "Taking dangerous risks helps me to prove myself;" Violence (8 items), "Sometimes violent action is necessary;" Dominance (4 items), "I should be in charge;" Playboy (12 items), "If I could, I would frequently change sexual partners;" Self-Reliance (6 items), "Asking for help is a sign of failure;" Primacy of Work (8 items), "My work is the most important part of my life;" Power Over Women (9 items), "In general, I control the women in my life;" Disdain for Homosexuals (10 items), "I make sure that people think that I am heterosexual;" and Pursuit of Status (6 items), "It feels good to be important."
The CMNI demonstrates strong validity (Mahalik et al., 2003). CMNI scores are related significantly and positively to other measures of masculinity, such as the Gender Role Conflict Scale and the Male Gender Role Stress Scale, indicating good convergent validity (Mahalik et al., 2003). Men and women differ significantly on CMNI scores in the expected direction. The CMNI also was correlated with a range of health-related behaviors, such as violence, law breaking, and tobacco and alcohol use. There is also support for the concurrent validity of the CMNI because it is related to psychological distress and negative attitudes toward seeking psychological help. Some of the norms were also associated with social dominance, aggression, and a desire to increase muscle mass. Test-retest reliability is reported as .95 for the total CMNI score and as ranging from .95 to .51 for the subscales, and internal consistency estimates yield an alpha of .94 for the total CMNI and a range from .72 to .91 for the subscales (Mahalik et al., 2003).

To examine how men's conformity to masculine norms influences both men's and women's relationship satisfaction, we used two versions of the CMNI in the present study. Men filled out the standard CMNI measure in regard to themselves. Women completed a modified version of the CMNI that measured their perception of their most recent romantic male partner's conformity to traditional masculine norms. For example, the item "In general, I will do anything to win," became "In general, he will do anything to win." Rochlen and Mahalik (2004) used similar technique in a study on women's perceptions of male partners' gender role conflict as a predictor of relationship satisfaction.

Relationship Assessment Scale (RAS). The RAS (Hendrick, Dicke, \& Hendrick, 1998) consists of seven statements of relationship satisfaction measured on a 5-point Likert scale. The RAS measures general satisfaction, how well the partner meets one's needs, how well the relationship compares with others, regrets about the relationship, how well one's expectations have been met, love for the partner, and problems in the relationship (Hendrick et al., 1998). For instance, items include, "How good is your relationship compared to most?" "To what extent has your relationship met your original expectations?" and "How often do you wish you 
hadn't gotten into this relationship?" Respondents are instructed, "Please answer in regards to your most recent romantic relationship. If you have never had a romantic relationship, please answer in regards to your best opposite sex friend and check here" (a blank is provided). In addition, we asked, "Are you still in the relationship you referred to above?" (respondents checked "yes" or "no") and "What is/was the length of the above relationship? (__years _ months)."

The RAS demonstrates high test-retest reliability $(r=.85)$ and internal consistency $(\alpha=$ .86). Convergent validity of the instrument is high; correlations between the RAS and two other measures of relationship satisfaction (the Dyadic Adjustment Scale and the Kansas Marital Satisfaction Scale) range from .64 to .80 (Hendrick et al., 1998; Vaughn \& Baier, 1999).

\section{Procedure}

The two researchers, one man and one woman, introduced themselves and briefly described the study at the beginning of each of the nine introductory psychology classes. One passed out the female version of questionnaires, and one passed out the male version. The packet consisted of an informed consent form, a demographic questionnaire, the CMNI, and the RAS. All responses were anonymous. Participants were instructed to read the informed consent and sign it prior to beginning the packet and, on completion, to sit quietly until the researchers collected them. Some students received extra credit from their instructors for participating. All participants were treated in accordance with American Psychological Association ethical guidelines.

\section{Results}

\section{Preliminary Analyses}

Of the 307 participants, $90.55 \%$ reported having had a romantic relationship. The length of the participants' relationships ranged from 1 to 72 months, with a mean of 13.60 months and a standard deviation of 12.27. Participants reporting never having had a romantic relationship were excluded from analyses $(n=25)$. The distributions of the excluded participants on demographic variables were similar to that of in- cluded participants, although excluded participants were slightly more likely to be 1st-year students $(64 \%$ vs. $61 \%)$ and male $(60 \%$ vs. $55 \%$ ). The reliabilities of the scales and subscales were comparable with past research using the CMNI and RAS. For this sample, Cronbach's alpha for the CMNI was .78 and the majority of Cronbach's alphas for the CMNI subscales ranged from .80 to .90 , although two had alphas of .66. Cronbach's alpha for the RAS with this sample was .86. Length of relationship was not associated with CMNI scores or RAS scores. The RAS scores of women $(M=27.22)$ and men $(M=26.01)$ did not significantly differ, $t(273)=-1.76, p>.05$. However, men $(M=33.89)$ and women's $(M=35.09)$ CMNI scores did differ significantly, $t(214)=-2.67$, $p<.01$. Table 1 shows the means and standard deviations of study variables, separated by gender.

\section{Primary Analyses}

Results supported Hypothesis 1 that conformity to traditional masculine norms as measured by the CMNI would be negatively associated with intimate relationship satisfaction as measured by the RAS for both women and men (see Table 1). In short, women perceiving that their male partners conformed more to traditional masculinity norms were less satisfied with their relationships. Likewise, men that are more conforming to traditional male norms were also less satisfied with their intimate relationships.

Hypothesis 2 predicted that the Emotional Control, Self-Reliance, Risk-Taking, Playboy, Power Over Women, Dominance, Violence, Winning, Pursuit of Status, and Primacy of Work subscales would be negatively correlated with relationship satisfaction for both women and men. Hypothesis 2 was partially supported. Women's ratings of their male partners on the CMNI subscales (with the exception of Pursuit of Status) were negatively correlated with decreased relationship satisfaction as measured by the RAS. This suggests that women perceiving their male partners as less conforming to masculinity norms of emotional control, winning, desire for multiple partners (playboy), violence, disdain for homosexuals, dominance, primacy of work, power over women, self-reliance, and risk taking were more satisfied with their rela- 
Table 1

Conformity to Masculine Norms Inventory (CMNI) Subscale Means, Standard Deviations, and Correlations With Relationship Satisfaction

\begin{tabular}{|c|c|c|c|c|c|c|}
\hline \multirow[b]{2}{*}{ Subscale } & \multicolumn{3}{|c|}{ Women } & \multicolumn{3}{|c|}{ Men } \\
\hline & $M$ & $S D$ & $r$ & $M$ & $S D$ & $r$ \\
\hline Dominance & 2.51 & 0.46 & $-.40 * * *$ & 2.45 & 0.43 & $-.14 *$ \\
\hline Emotional Control & 2.43 & 0.55 & $-.26^{* * *}$ & 2.37 & 0.46 & -.11 \\
\hline Disdain for Homosexuals & 2.88 & 0.59 & $-.29 * *$ & 2.73 & 0.51 & -.13 \\
\hline Playboy & 1.86 & 0.52 & $-.57 * * *$ & 1.89 & 0.50 & $-.45^{* * * *}$ \\
\hline Risk-Taking & 2.75 & 0.43 & $-.39 * * *$ & 2.65 & 0.37 & $-.16^{*}$ \\
\hline Self-Reliance & 2.43 & 0.54 & $-.28 * *$ & 2.17 & 0.47 & -.13 \\
\hline Pursuit of Status & 3.00 & 0.34 & -.10 & 2.90 & 0.41 & -.03 \\
\hline Violence & 2.61 & 0.47 & $-.28 * *$ & 2.70 & 0.47 & $-.15^{*}$ \\
\hline Winning & 2.57 & 0.47 & $-.34 * * *$ & 2.52 & 0.47 & .06 \\
\hline Power Over Women & 2.22 & 0.32 & $-.42 * * *$ & 2.06 & 0.30 & $-.18^{*}$ \\
\hline Primacy of Work & 2.21 & 0.47 & $-.24 * *$ & 2.10 & 0.46 & .05 \\
\hline CMNI Sum & 35.09 & 4.37 & $-.53 * * *$ & 33.88 & 3.37 & $-.27 * *$ \\
\hline RAS Sum & 27.22 & 5.94 & & 26.01 & 5.66 & \\
\hline
\end{tabular}

Note. For women, $n$ s ranged from 105 to 125 ; for men, $n$ s ranged from 117 to 153 . RAS $=$ Relationship Assessment Scale. $* p<.05$, one-tailed. $* * p<.01$, one-tailed. $* * * p<.001$, one-tailed.

tionships. Contrary to expectation, men's RAS scores were negatively correlated with only five CMNI subscales (Playboy, Risk-Taking, Dominance, Violence, and Power Over Women), and, with the exception of the Playboy subscale, the correlations were only marginally significant $(p<.05)$. To summarize, Hypothesis 2 was largely supported in regard to women and only somewhat in regard to men. Although this was unexpected, it does support the thinking that conformity to traditional masculinity differentially influences the relationship satisfaction of women and men (Hypothesis 3).

Hypothesis 3 predicted that the negative relationship between overall CMNI scores and relationship satisfaction would be stronger for women rating their male partners than it would be for men rating themselves. Fisher's $r$-to- $z$ transformation for comparing independent $r \mathrm{~s}$ was used to determine the significance of the difference between the $r$ s for men and the $r$ s for women (this procedure is described in Cohen, Cohen, West, \& Aiken, 2003, p. 49). The correlation between the CMNI and RAS for women was found to differ significantly from the correlation for men $(p<.01)$. The difference between men and women's $r$ s for the Winning subscale $(p<.01)$ was significant, and Dominance, Emotional Control, Power Over Women, and Primacy of Work were marginally significant $(p<.05$; note that because of the large number of comparisons, a more conservative alpha of .01 was used to reduce Type I error and the Bonferroni correction was used to correct for familywise error rates).

The CMNI and the CMNI subscales were expected to account for a greater portion of the variance in relationship satisfaction for women in comparison with men. To obtain the $R^{2}$ of men and of women for comparison, we conducted a hierarchical regression procedure separately for men and women with RAS as the dependent variable and the 11 subscales entered in one block as predictor variables (see Table 2 for unstandardized and standardized beta coefficients). For women, $R^{2}$ was $.421, F(11$, $93)=6.14, p<.001$. For men, $R^{2}$ was .256 , $F(11,228)=7.12, p<.001$. The confidence interval for the difference between the $R^{2} \mathrm{~s}$ was computed following Cohen et al. (2003). The 95\% confidence interval did not include zero, indicating that the difference between the $R^{2} \mathrm{~s}$ was significant at the .05 level. In addition, it should be noted that with all variables entered, the only subscale that predicted a unique portion of the variance in RAS over and beyond the other variables was the Playboy subscale. This was true for both men and women. In summary, these findings support the hypothesis that men's conformity to traditional masculine norms is more strongly associated with women's rela- 
Table 2

Summary of Hierarchical Regression Analysis for Conformity to Masculine Norms Inventory Subscales Predicting Relationship Assessment Scale Scores

\begin{tabular}{|c|c|c|c|c|c|c|}
\hline \multirow[b]{2}{*}{ Subscale } & \multicolumn{3}{|c|}{ Women } & \multicolumn{3}{|c|}{ Men } \\
\hline & $B$ & $S E B$ & $\beta$ & $B$ & $S E B$ & $\beta$ \\
\hline Dominance & -0.50 & 0.37 & -.17 & -0.45 & 0.23 & -.14 \\
\hline Emotional Control & 0.05 & 1.16 & .004 & 0.41 & 0.79 & .04 \\
\hline Disdain for Homosexuals & -1.45 & 0.91 & -.14 & -1.09 & 0.67 & -.10 \\
\hline Playboy & -4.97 & 1.15 & $-.44 * * *$ & -4.55 & 0.79 & $-.40 * * *$ \\
\hline Risk-Taking & -1.08 & 1.38 & -.08 & -1.21 & 0.94 & -.09 \\
\hline Self-Reliance & 0.95 & 1.21 & .09 & -0.95 & 0.75 & -.09 \\
\hline Pursuit of Status & 1.32 & 1.52 & .08 & 1.16 & 0.98 & .08 \\
\hline Violence & -0.41 & 1.19 & -.03 & -0.45 & 0.78 & -.04 \\
\hline Winning & -1.00 & 1.48 & -.08 & 1.08 & 0.88 & .09 \\
\hline Power Over Women & -0.39 & 1.97 & -.02 & 0.81 & 1.32 & .05 \\
\hline Primacy of Work & -1.12 & 1.25 & -.09 & -0.53 & 0.81 & -.04 \\
\hline
\end{tabular}

$* * * p<.001$.

tionship satisfaction than it is with men's relationship satisfaction.

\section{Discussion}

This study examined the association between men's conformity to traditional masculine norms and the relationship satisfaction of men and their female romantic partners. Results supported the hypothesis that conformity to traditional masculine norms is negatively associated with intimate relationship satisfaction, especially the satisfaction of women. The study confirms Levant's (1996) proposition that the relationship difficulties experienced by some men may stem from the norms of the traditional masculine role. The findings are also consistent with the gender role strain paradigm, in particular the concept of dysfunction strain, because it appears that fulfilling the requirements of the traditional male role may lead to negative outcomes for men's relationships with others.

The study findings indicate that men's conformity to traditional masculine norms more greatly influences the relationship satisfaction of women. For women, all CMNI subscales were significantly correlated with decreased relationship satisfaction, with the exception of the Pursuit of Status subscale. The absence of a significant association between Pursuit of Status and relationship satisfaction may indicate that women's relationship satisfaction is unrelated to men's ability to materially satisfy them, or it may be that in this college-aged sample, the pursuit of status has less impact on relationships than it would in an older sample. Some of these norms that were negatively correlated with relationship satisfaction, such as emotional control, self-reliance, primacy of work, and risk taking may be negatively correlated with relationship satisfaction for women because conformity to these norms may reduce men's emotional and physical availability. These norms are also consistent with a relational independence that may be perceived by women as at odds with the relational interdependence they desire. The Playboy, Power Over Women, Dominance, Winning, and Violence subscales may be negatively associated with relationship satisfaction because they may lead to attitudes and behaviors that are considered disrespectful by women. Conformity to some of these norms, such as winning, dominance, and power over women, may also translate into a competitive orientation that interferes with cooperative conflict resolution.

For men, only the Playboy subscale was significantly associated with decreased relationship satisfaction, although the Dominance, Risk-Taking, Violence, and Power Over Women subscales were marginally associated with relationship satisfaction, perhaps because of their association with relational conflict. However, conformity to the playboy norm also appears to be at odds with satisfaction with a monogamous relationship because it includes agreement with items such as, "If I could, I would frequently change sexual partners," and 
disagreement with items such as, "I only get romantically involved with one person." It remains unclear whether these gender differences are because men's relational standards are different than women's or whether men's conformity to masculine norms more negatively impacts women's emotional needs (i.e., highly conforming men may provide less emotional support but still receive adequate emotional support from their female partners).

Although significant correlations were found between conformity to traditional masculinity norms and relationship satisfaction, this correlational study leaves many questions unanswered. For instance, is men's conformity to risk taking negatively related to relationship satisfaction because it contributes to substance abuse and decreased emotional support, because the relationship suffers from increased conflict, or both? Does conformity to traditional masculine norms decrease women's relationship satisfaction or does decreased relationship satisfaction lead women to negatively stereotype their male partners as conforming to traditional masculinity norms? The regression analyses finding that the Playboy subscale was the only subscale (for both men and women) that predicted a unique portion of the variance in relationship satisfaction over and beyond the other subscales is also intriguing. Although it seems to underscore the unique influence of emotional and sexual fidelity in romantic relationships, the causal direction of the relationship is unclear and may even be different for men than it is for women. For men, it could be a symptom of relationship dissatisfaction or a source of it if they desire sexual variety. For women, it is more likely to be a cause of relationship dissatisfaction.

In addition to the correlational nature of the study, another limitation stems from a primarily Euro American, college-aged sample that reduces our ability to generalize results. It is possible that the relationship between conformity to masculine norms and relationship satisfaction may be different in other samples. Likewise, the study focused on heterosexual romantic relationships. Ideally, the research should be replicated with more diverse samples and with couples that present with relationship difficulties to counselors or other mental health professionals.

One of the next steps for research with the CMNI is to develop and test counseling inter- ventions using the CMNI as a counseling tool. The use of the CMNI in counseling may be most effective if counselors take into account past scholarship on counseling and men. For instance, Kelly and Hall (1992) cautioned those counseling men to resist the tendency to pathologize masculinity and alienate clients. Instead, they recommended that counselors affirm the assets male clients bring to counseling. Past research also indicates that problem solving and other creative approaches, versus approaches that are feelings focused, may be most effective with men (Chang, Yeh, \& Krumboltz, 2001; Robertson \& Fitzgerald, 1992; Wilcox \& Forrest, 1992). Addis and Mahalik (2003) suggested that counseling interventions with men are more likely to be effective when they present the problems facing men as "normal" and when they lead men to associate counseling with emotional strength and other masculine values, such as courage.

Applying this scholarship on counseling and men, a proposed counseling model using the CMNI is as follows. First, it is recommended that to avoid pathologizing masculinity and creating client resistance, counselors should consider using the client's CMNI responses to explore the situations in which their conformity to the norms of masculinity is adaptive and desirable and the situations, such as the intimate relationship, where such conformity may be less adaptive. Second, psychoeducation on the research on masculinity and relationship intimacy can be used to normalize the impact of masculinity on men's relationships by showing that this is a common issue facing men. Third, psychoeducation regarding the male socialization process is also recommended to prevent male clients from feeling shamed, blamed, and defective (and consequently defensive). Understanding the social context in which masculinity operates may also help both male and female clients to see problem attitudes and behaviors as learned and changeable rather than as "hardwired" and immutable. The therapist can cast resistance to these powerful conformity pressures in terms of traditional male strengths, such as courage and self-reliance. Fourth, in couples counseling, reciprocal empathy regarding the impact of conformity to masculine norms should be promoted. Structured techniques that ensure that both parties share and mirror in a calm emotional field may be most effective in 
keeping male clients productively engaged in the therapeutic process. Female clients need to develop empathy for the past and present conformity pressures facing their male partners (including those they impose on their male partners), and male clients need empathy regarding the impact of their conformity to masculine norms on their female partners. Both partners need empathy regarding the others' relational standards so that partners can act accordingly instead of assuming that their partner's needs are the same as theirs. Finally, once mutual empathy has been attained, a collaborative problem-solving approach can be used to develop a mutually agreed on plan of action.

In conclusion, many masculinity researchers hope that an increased understanding of the dysfunctional aspects of traditional masculinity can lead to improved psychological services for men and reduce relationship distress. Although the limited sample restricts our ability to generalize study results, this research provides additional evidence of the harmful effects of traditional masculinity. It also supports Ludlow and Mahalik's (2001) contention that the CMNI has potential clinical utility. In particular, the CMNI could be a useful tool when counseling couples and male clients with relationship problems.

\section{References}

Addis, M. E., \& Mahalik, J. R. (2003). Men, masculinity, and the contexts of help seeking. American Psychologist, 58, 5-14.

Antill, J. K. (1983). Sex role complementarity versus similarity in married couples. Journal of Personality and Social Psychology, 45, 145-155.

Boyd, K. L. (1995). The relationship between selfdisclosure, intimacy, and satisfaction in AfricanAmerican and European-American heterosexual relationships. Dissertation Abstracts International, 55(9), 4112B.

Burleson, B. R., Kunkel, A. W., Samter, W., \& Werking, K. J. (1996). Men's and women's evaluations of communication skills in personal relationships: When sex differences make a difference-and when they don't. Journal of Social and Personal Relationships, 13, 201-224.

Burn, S. M. (1996). The social psychology of gender. New York: McGraw-Hill.

Campbell, J. L., \& Snow, B. M. (1992). Gender role conflict and family environment as predictors of men's marital satisfaction. Journal of Family Psychology, 6, 84-87.
Chang, T., Yeh, C. J., \& Krumboltz, J. D. (2001). Process and outcome evaluation of an on-line support group for Asian American male college students. Journal of Counseling Psychology, 48, 319-329.

Cohen, J., Cohen, P., West, S. G., \& Aiken, L. S. (2003). Applied multiple regression/correlation analysis for the behavioral sciences (3rd ed.). Mahwah, NJ: Erlbaum.

Cournoyer, R. J., \& Mahalik, J. R. (1995). Crosssectional study of gender role conflict examining college-aged and middle-aged men. Journal of Counseling Psychology, 42, 11-19.

Cutrona, C. (1996). Social support in couples. Thousand Oaks, CA: Sage.

Dindia, K., \& Allen, M. (1992). Sex differences in self-disclosure: A meta-analysis. Psychological Bulletin, 112, 106-124.

Foubert, J. D., \& Sholley, B. K. (1996). Effects of gender, gender roles, and individualized trust on self-disclosure. Journal of Social Behaviors and Personality, 11, 277-288.

Gottman, J. (1994). Why marriages succeed or fail. New York: Simon \& Schuster.

Hendrick, S. S., Dicke, A., \& Hendrick, C. (1998). The Relationship Assessment Scale. Journal of Social and Personal Relationships, 15, 137-142.

Ickes, W. (1985). Sex-role influences on compatibility in relationships. In W. Ickes (Ed.), Compatible and incompatible relationships (pp. 187-208). New York: Springer-Verlag.

Ickes, W. (1993). Traditional gender roles: Do they make, and then break, our relationships? Journal of Social Issues, 49, 71-85.

Jones, D. C. (1991). Friendship satisfaction and gender: An examination of sex differences in contributors to friendship satisfaction. Journal of Social and Personal Relationships, 8, 167-185.

Jones, G. P., \& Dembo, M. H. (1989). Age and sex role differences in intimate friendships during childhood and adolescences. Merrill-Palmer Quarterly, 35, 445-462.

Kelly, K. R., \& Hall, A. S. (1992). Toward a developmental model for counseling men [Special issue]. Journal of Mental Health Counseling, 14, 257-273.

Kurdek, L., \& Schmitt, J. (1986). Interaction of sexrole self-concept with relationship quality and relationship beliefs in married, heterosexual, cohabitating, gay, and lesbian couples. Journal of Personality and Social Psychology, 51, 365-370.

Lamke, L. (1989). Marital adjustment among rural couples: The role of expressiveness. Sex Roles, 21, 579-590.

Lamke, L., Sollie, D. L., Durbin, R. G., \& Fitzpatrick, J. A. (1994). Masculinity, femininity, and relationship satisfaction: The mediating role of in- 
terpersonal competence. Journal of Social and Personal Relationships, 11, 535-554.

Levant, R. F. (1996). The new psychology of men. Professional Psychology: Research and Practice, 27, 259-265.

Levant, R. F., Hirsch, L. S., Celentano, E., Cozza, T. M., Hill, S., MacEachern, M., et al. (1992). The male role: An investigation of contemporary norms. Journal of Mental Health Counseling, 14, 325-337.

Ludlow, L. H., \& Mahalik, J. R. (2001). Congruence between a theoretical continuum of masculinity and the Rasch model: Examining the Conformity to Masculine Norms Inventory. Journal of Applied Measurement, 2, 205-226.

Mahalik, J. R., Locke, B. D., Ludlow, L. H., Diemer, M. A., Gottfried, M., Scott, R. P. J., \& Freitas, G. (2003). Development of the Conformity to Masculine Norms Inventory. Psychology of Men \& Masculinity, 4, 3-25.

McGraw, S. L. (2001). Masculinity ideologies, men's relationship behavior, and relationship satisfaction in heterosexual couple relationships. Dissertation Abstracts International, 62(3), 1588B.

Miller, L., Berg, J. H., \& Archer, R. L. (1983). Openers: Individuals who elicit intimate self-disclosure. Journal of Personality and Social Psychology, 44, 1234-1244.

O'Neil, J. M. (1981). Patterns of gender role conflict and strain: Sexism and fear of femininity in men's lives. The Personnel and Guidance Journal, 60, 203-210.

O’Neil, J. M., Good, G. E., \& Holmes, S. (1995). Fifteen years of theory and research on men's gender role conflict: New paradigms for empirical research. In R. F. Levant \& W. S. Pollack (Eds.), A new psychology of men (pp. 164-206). New York: Basic Books.

O'Neil, J. M., Helms, B., Gable, R., David, L., \& Wrightsman, L. (1986). Gender-Role Conflict Scale: College men's fear of femininity. Sex Roles, 14, 335-350.

Pleck, J. H. (1981). The myth of masculinity. Cambridge, MA: MIT Press.

Pleck, J. H. (1995). The gender role strain paradigm: An update. In R. F. Levant \& W. S. Pollack (Eds.), A new psychology of men (pp. 11-32). New York: Basic Books.

Pleck, J. H., Sonenstein, F. L., \& Ku, L. C. (1993). Masculinity ideology: Its impact on adolescent males' heterosexual relationships. Journal of Social Issues, 49, 11-29.
Robertson, J. M., \& Fitzgerald, L. F. (1992). Overcoming the masculine mystique: Preferences for alternative forms of assistance among men who avoid counseling. Journal of Counseling Psychology, 39, 240-246.

Rochlen, A. B., \& Mahalik, J. R. (2004). Women's perceptions of male partners' gender role conflict as predictors of psychological well-being and relationship satisfaction. Psychology of Men \& Masculinity, 5, 147-157.

Ruble, T. L., \& Scheer, J. A. (1994). Gender differences in conflict-handling styles: Less than meets the eye? In A. Taylor \& J. B. Miller (Eds.), Conflict and gender (pp. 155-166). Cresskill, NJ: Hampton Press.

Sapadin, L. A. (1988). Friendship and gender: Perspectives of professional men and women. Journal of Social and Personal Relationships, 5, 387-403.

Sharpe, M. J., \& Heppner, P. P. (1991). Gender, role, gender role conflict, and psychological well-being in men. Journal of Counseling Psychology, 38, 323-330.

Sharpe, M. J., Heppner, P. P., \& Dixon, W. A. (1995). Gender role conflict, instrumentality, expressiveness, and well-being in adult men. Sex Roles, 33, 1-18.

Siavelis, R. L., \& Lamke, L. K. (1992). Instrumentalness and expressiveness: Predictors of heterosexual relationship satisfaction. Sex Roles, 26, $149-159$.

Stapley, J. C., \& Haviland, J. M. (1989). Beyond depression: Gender differences in normal adolescents' emotional expression. Sex Roles, 20, 295308.

Thompson, E. H., Jr., \& Pleck, J. H. (1986). The structure of male role norms. American Behavioral Scientist, 29, 531-543.

Vangelisti, A. L., \& Daly, J. A. (1997). Gender differences in standards for romantic relationships. Personal Relationships, 4, 203-219.

Vaughn, M. J., \& Baier, M. E. (1999). Reliability and validity of the Relationship Assessment Scale. American Journal of Family Therapy, 27, 137147.

Wilcox, D. W., \& Forrest, L. (1992). The problems of men and counseling: Gender bias or gender truth? Journal of Mental Health Counseling, 14, 291304. 